\title{
Understanding and addressing gender equity for women in neurology
}

Julie K. Silver, MD

Neurology ${ }^{\circledR}$ 2019;93:538-549. doi:10.1212/WNL.0000000000008022

\section{Correspondence}

Dr. Silver

julie_silver@

hms.harvard.edu

\section{RELATED ARTICLE}

Special Editorial

Efforts by the journal to promote perspectives of equity, diversity, and inclusion and address disparities

Page 521

MORE ONLINE

ค Podcast

Dr. Stacey Clardy talks with Dr. Julie Silver about her paper on understanding and addressing gender equity for women in neurology.

NPub.org/9bpps1 


\section{Glossary}

AAN = American Academy of Neurology; CV = curriculum vitae; NASEM = National Academies of Science, Engineering and Medicine; ROI $=$ return on investment.

A landmark moment occurred in 2017 , when for the first time women accounted for more than half $(50.7 \%)$ of incoming US medical students. ${ }^{1}$ One might think then that medicine, with its large proportion of intelligent and highly trained women physicians and scientists, is leading the way in gender equity. Yet it is not. In fact, in many cases research shows slow progress, ${ }^{2}$ no progress, ${ }^{3}$ or even regression ${ }^{4,5}$ in workforce gender equity. A robust evidence base, primarily reflecting that most gender equity research occurs in academic medicine, demonstrates disparities for women in compensation, ${ }^{6}$ promotion, ${ }^{7}$ research funding, ${ }^{8}$ recognition awards, ${ }^{4,9-11}$ journal editorial board representation, ${ }^{5,12}$ publishing, ${ }^{13,14}$ speaking, ${ }^{15-17}$ workplace environments, ${ }^{18}$ and recruitment/retention offers. ${ }^{18}$ Disparities in promotion start early in women's careers and the gaps become more pronounced over time. For example, women account for $47.4 \%$ of assistant professors $(1,308$ of 2,760$), 38.5 \%$ of associate professors ( 474 of 1,231 ), and $20.8 \%$ of professors (297 of 1,429) in neurology. ${ }^{19}$ Although the greatest disparities for women in the academic track occur at the professor level, including in neurology, ${ }^{20}$ Schor $^{21}$ found that among senior level leadership, only $15 \%$ of US medical school deans were women. Even in surgical specialties, the low number of women at the highest levels is inconsistent with the available pipeline, and Dr. Keith Lillemoe stated the following in his 2017 presidential address to the American Surgical Association: "The number of outstanding, qualified female candidates is more than adequate to fill every open surgical leadership position in America today. The problem is not the pipeline-it is the process." 22

Despite the disparities, Carr et al. ${ }^{23}$ found that $40 \%$ of the academic institutions they studied had no programs for recruiting, promoting, or retaining women (frequently describing such programming as unnecessary). Indeed, structural and institutional bias are increasingly recognized as factors in gender disparities, while conventional reasons such as lack of qualified women (insufficient or leaky pipeline) are being refuted., ${ }^{9,1324}$ However, midcareer and senior women in medicine, including but not limited to those in neurology, have faced years of implicit (unconscious) bias, which at times rose to the level of explicit (conscious) bias-slowing their career growth, causing them to be overlooked for well-deserved recognition and promotions, and making them uncomfortable and even unsafe in their workplaces. Importantly, although this report is focused primarily on women physicians and researchers, there is no doubt that it is imperative to address inclusion and safety for every worker, student, and patient-across gender, ethnic, racial, sexual orientation, ability level, and other factors that may make them vulnerable to mistreatment such as bullying, harassment, bias, or discrimination.

\section{The inequity spectrum}

Research on gender disparities demonstrates a spectrum of inequities that range from microinequities to macroinequities, ${ }^{25}$ with the latter having easily identifiable and quantifiable metrics (e.g., compensation or promotion). While studies of microinequities are frequently quantitative and report data, the metrics used are often unique and sometimes quite creative. For example, one microinequity study demonstrated via video recordings of Grand Rounds speaker introductions that when compared with men, women's professional titles were used less frequently. ${ }^{17}$ In a study assessing the representation of men and women physicians (and information about their work) in newsletters published by the American Academy of Physical Medicine and Rehabilitation over a period of more than 5 years, my colleagues and I found that while men were always included, women were completely excluded from more than one-third of the newsletters. ${ }^{26}$ In another study, we found that women were represented at lower than expected levels among authors of perspective-type articles published in the 4 highest-impact pediatric journals. ${ }^{13}$ These types of studies have added to a growing body of evidence demonstrating how women are often subtly marginalized, silenced, or made invisible. The building of one's professional reputation is both vital and nuanced, ${ }^{27}$ and the cumulative effect of many subtle slights may have a more pronounced effect on women's careers than previously recognized.

\section{Gender bias and sexual harassment}

Gender bias and disparities likely provide fertile ground for sexual harassment, and it is clear that medicine has a serious problem with these issues. The landmark report from the National Academies of Science, Engineering and Medicine (NASEM) titled Sexual Harassment of Women: Climate, Culture, and Consequences in Academic Sciences, Engineering, and Medicine stated that "gender discrimination itself harms women and the broader meritocracy of science. And thus we conclude that together, gender discrimination and male domination are features of the academic science, engineering, and medicine climate that create a permissive environment for sexual harassment." 28 The report describes the normalization of gender-related harassment (including but not limited to sexual harassment) in medicine, and sheds light on the current literature. Relevantly, the true incidence and prevalence is likely underestimated for a variety of reasons (e.g., underreporting by those affected, reluctance to label offending, demeaning, or intrusive behavior as harassment, or failure to follow good research practices). As the report explains, large 
proportions (and in some studies the majority) of women in academia in general, inclusive of health care training environments such as medical schools and academic medical centers, are targets. For example, surveys of 2 large institutions revealed that $45 \%$ to nearly $50 \%$ of women medical student respondents had experienced incidents of faculty/staff-on-student sexist hostility. ${ }^{28}$ Moreover, women medical student respondents were more likely to have experienced faculty/staff-on-student sexist hostility than their same-institutional-system peers in undergraduate, graduate, non-science-engineering-medicine, science, and engineering studies. ${ }^{28}$ Importantly, it is becoming increasingly clear that in some instances medical schools and other health care organizations have one or more serial harassers who have continued their behavior over the course of many years and affected many targets (generally women, but men and others across the gender spectrum as well). Bystanders who have witnessed or heard about this behavior also may have been negatively affected (figure 1). Although the vast majority of men in medicine are professional and respectful of those with whom they interact and there is no evidence to suggest that most men are guilty of harassment, authors of the NASEM report concluded that "Environments where men outnumber women, leadership is male dominated, and/or jobs or occupations are considered atypical for women have more frequent incidents of sexual harassment for women. " 28 Therefore, likely a small group of people, primarily though not exclusively men, who are too often serial harassers or predators are poisoning medicine's learning and working environments.

The key to changing the normalization of sexual harassment then is to recognize that health care leaders' actions aimed at

Figure 1 Sexual harassment in medicine

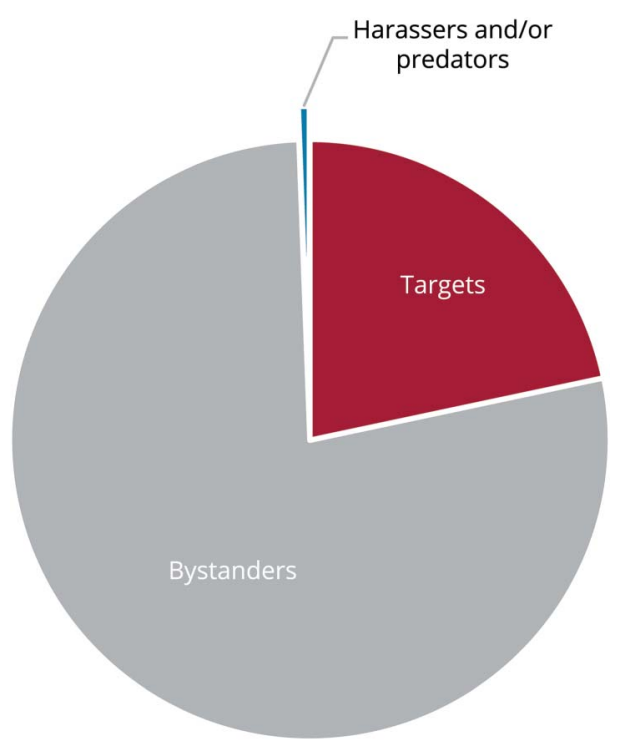

This graphic is inclusive of all genders and is intended to show that the proportion of serial harassers or predators (which is unknown) is a much smaller group compared to targets and bystanders. ridding their institutions of toxic behavior exhibited by a proportionally small group of people will determine what happens in the future to a much larger group of people. For example, a few months following the release of the NASEM report, NIH Director Francis Collins acknowledged that sexual harassment is "morally indefensible, it's unacceptable, and it presents a major obstacle that is keeping women from achieving their rightful place in science." 29 He went further to issue a formal apology, stating, "To all those who have endured these experiences, we are sorry that it has taken so long to acknowledge and address the climate and culture that has caused such harm." ${ }^{29} \mathrm{Fi}$ nally, he acknowledged, "We are concerned that NIH has been part of the problem [and] we are determined to become part of the solution." ${ }^{29}$ In response, the $\mathrm{NIH}$ launched a website with new resources and policies aimed at reducing sexual harassment in academic medicine. ${ }^{30}$ Similarly, Time's Up Healthcare launched in early 2019 as a not-for-profit affiliate of the Time's Up organization formed in response to the \#MeToo movement and focused on ensuring an equitable and safe environment for everyone. $^{31}$

Whatever form they take, the evidence demands that both gender discrimination and sexual harassment, which are overwhelmingly directed at women, must be recognized by the medical and scientific community as morally indefensible and unethical:

1. Discrimination is antithetical to the tenets of professionalism in medicine. ${ }^{32}$

2. Gender discrimination itself harms women, and supports organizational environments in which sexual harassment has been normalized. ${ }^{28}$

3. Sexual harassment itself is a form of discrimination. ${ }^{28}$

4. Academia has a high prevalence of sexual harassment. ${ }^{28}$

5. "By far, the greatest predictors of the occurrence of sexual harassment are organizational." 28

6. Gender equity is a moral imperative. ${ }^{33}$

Therefore, we must conclude that leaders of all health carerelated organizations have a moral and ethical imperative to expeditiously address both gender discrimination and sexual harassment of women in medicine.

\section{Gender-related disparities for women physicians in neurology}

The evidence base regarding disparities for women in neurology-where women constitute approximately $45 \%$ of trainees, ${ }^{34} 30 \%$ of neurologists in practice, ${ }^{35}$ and $40 \%$ of faculty in academic medicine ${ }^{19}$-is growing and issues identified include compensation, ${ }^{6}$ academic promotion, ${ }^{7,20}$ leadership, ${ }^{36,37}$ recognition awards given by the American Academy of Neurology (AAN), ${ }^{10,16}$ journal editorial board representation, ${ }^{5,12}$ and publishing. ${ }^{20}$ 


\section{Physician compensation}

There is a spectrum of inequities that range from microinequities to macroinequities, ${ }^{25}$ but there is no doubt that compensation is among the most important. A growing body of published research and national surveys from Doximity, Medscape, and specialty societies collectively and undeniably demonstrate that disparities in compensation for women in medicine often exist even after accounting for variables such as part-time employment and differences in productivity. For example, in a study by Jena et al. ${ }^{6}$ looking at gender-related differences in academic physician salary in 24 US public medical schools across 12 states ( $n=10,241$ physicians; 3,549 women), researchers found that men in neurology $(\mathrm{n}=307)$ were paid an average of $\$ 30,482$ ( $95 \%$ confidence interval $\$ 9,731$ to $\$ 51,592)$ more than women annually $(n=142)$ even after adjusting for gender, age, years of experience, faculty rank, scientific authorship, NIH funding, clinical trial participation, and Medicare reimbursements. From these data, researchers estimated that women academic neurologists were making approximately 85 cents for every dollar or $85 \%$ of the adjusted salaries paid to colleagues who were men. ${ }^{6,38}$

While limitations are applicable to any research, including the Jena et al. ${ }^{6}$ study, I found it interesting to consider how compensation in neurology was ranked among the 18 different surgical and nonsurgical specialties included in the report. Among the 36 groups of men or women across 18 specialties, women in neurology were ranked last-earning the least amount annually compared to all of the others (figure 2). My comparison of same-specialty gender-related adjusted salaries revealed that the largest gap for women when compared with men among the 18 specialties was in neurology (15\%; range $-0.8 \%$ to $15 \%){ }^{6}$ Furthermore, women in neurology had the largest gap in salary as a percentage of same-gender specialtyrelated adjusted salary (figure $3 ; 17.7 \%$; range $-0.8 \%$ to $17.7 \%$ ).

To demonstrate the profound negative consequences this kind of pay disparity can have over the course of a woman neurologist's career, I utilized a set of publicly available online financial modeling tools. I found that if a woman received an additional $\$ 30,482$ in salary each year, after 40 years of investing and with adjustment for inflation, she would have a net return of $\$ 2,507,647$ (figure 4). ${ }^{39-41}$ Arguably, this is a conservative analysis, not taking into account that her return on investment (ROI) may be negatively affected by the possibilities that (1) at the beginning of her career, she could be paying a higher proportion of her salary toward debt and the money she owed may have been associated with an interest rate higher than the historical rate of return; and (2) as her career progressed, her rate of promotion may be slower and to a lower level overall (never reaching the highest levels) than her colleagues who are men. Although readers may take issue with elements of this example, no one should miss the main point: disparities in pay can generate a huge deficit in a person's financial standing over the course of a career.

\section{Leadership, academic promotion, and publishing}

Women neurologists also have been underrepresented in leadership positions and academic promotion, particularly to professor level, in neurology. ${ }^{5,19,36,37}$ Disparities in representation on editorial boards, especially at the highest levels, is also a pervasive problem in neurology as well as other specialties. ${ }^{5}$ Lack of equitable representation on journal editorial boards is itself a genderrelated disparity and it may also contribute to other disparities including those in publications, grant funding, academic promotion, leadership positions, and compensation. ${ }^{13,42,43}$ However, editorial board disparities have been shown to be relatively simple and inexpensive to fix and a number of journals, including some with high impact factors, have done so. ${ }^{44} \mathrm{~A}$ comment published by editors at The Lancet stated the following:

We have been involved in, and support efforts to expand, the adoption of the Sex and Gender Equity in Research (SAGER) Guidelines that address the inclusion of sex and gender analysis in research content. Complementary guidelines are under development (SAGER II) to provide a framework for publishers and journals to strive for gender balance in their workforce. The academic publishing community must recognise that it is not immune to sexism and gender bias. Now is the time to take decisive action to challenge the status quo. ${ }^{44}$

Importantly, the journal Neurology ${ }^{\circledR}$ is currently addressing disparities on its editorial board in an effort to be more diverse and inclusive. ${ }^{45}$

When my colleagues and I studied the largest or most influential professional societies associated with 39 different specialties, we found that during the most recent decade (2008-2017), 10 societies (26\%), including the AAN, had 0 years with a woman as president. ${ }^{37}$ Among these 10 societies, the AAN was associated with the third highest proportion of women in the specialty (28\%). The 2 societies associated with higher proportions of women in the field than neurology were dermatology (47\%) and pathology (37\%). The 7 remaining societies with 0 years with a woman as president were associated with specialties having much lower proportions of women in the field (5\%-18\%), including 5 surgical specialties. Notably, 15 specialty societies associated with lower percentages of women in the field than neurology ( $<28 \%$; and including 7 surgical specialties) had more years with a woman as president (1-4 years) than the AAN.

In the 71-year history of the AAN, there has been only 1 woman president, Sandra Olson, MD (2001-2003), and thereafter no woman led the AAN for 2 decades. In the future, Orly Avitzur, $\mathrm{MD}, \mathrm{MBA}$, is slated to be the second AAN president who is female (2021-2023). Given the growth of women in neurology and among members of the AAN, if history repeats itself and Dr. Avitzur is the sole woman president of the society during the next couple of decades, women would continue not only to be inequitably represented among presidents, but metrics would demonstrate a regression in progress toward gender equity in leadership. 
Figure 2 Rank of academic physicians' salary by specialty and gender

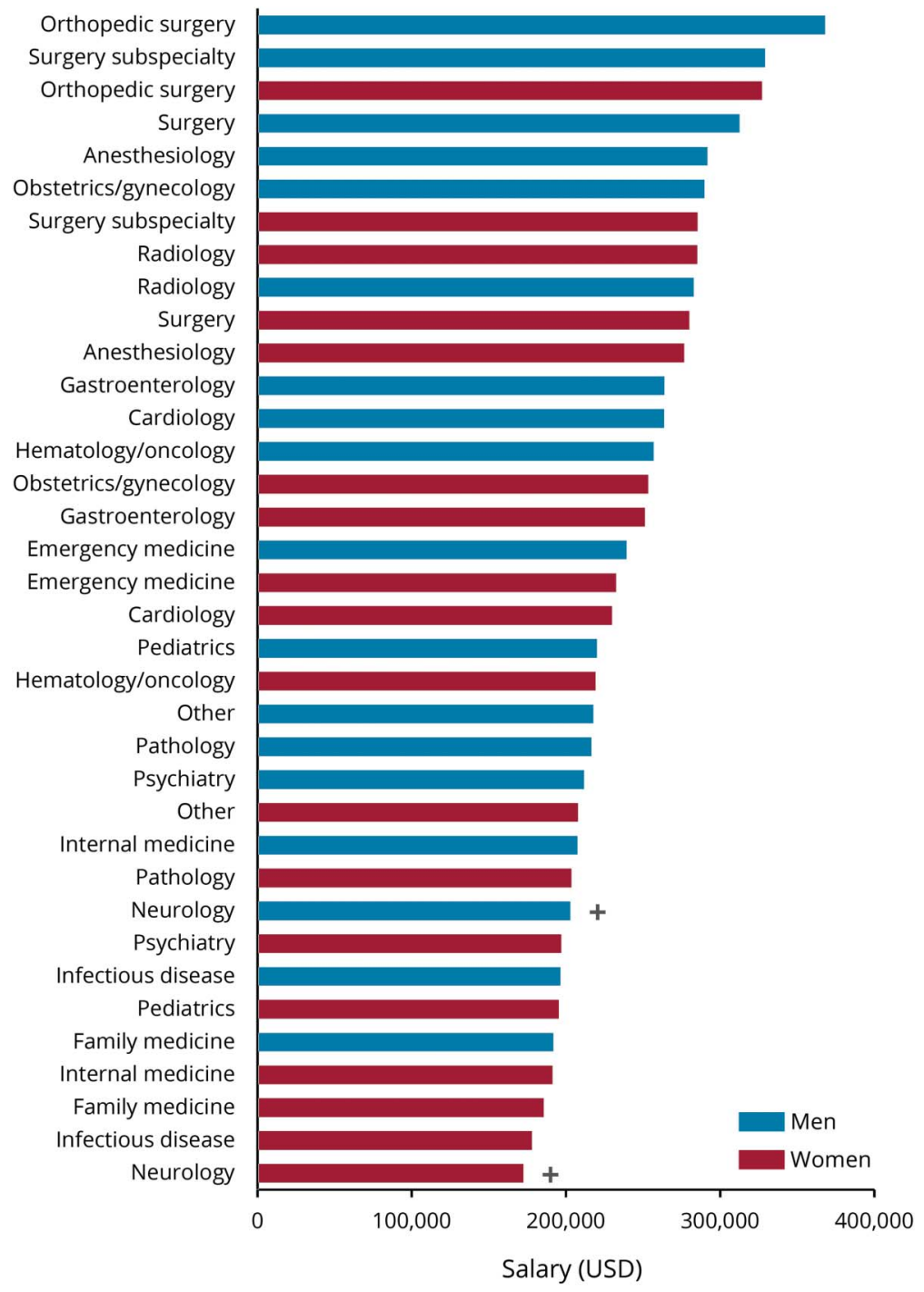

To examine the rank of academic physicians' salary by specialty and gender, the adjusted salaries* of men and women practicing in 18 specialties at 24 US medical schools across 12 states as determined by Jena et al. ${ }^{6}$ were sorted from largest to smallest. Women physicians in neurology were ranked 36 of 36 , and 8 steps below men physicians in neurology (+). *Adjustments included those for gender, age, years of experience, faculty rank, scientific authorship, NIH funding, clinical trial participation, and Medicare reimbursements.

This example demonstrates a serious issue in gender equity research - there is a difference between celebrating a woman's accomplishments (Drs. Olson's and Avitzur's elections) and suggesting that these accomplishments represent organizational progress in gender equity. ${ }^{46}$ Instead, to avoid undermining real progress in gender equity as well as identify and address gaps, we must use scientific methodology along with a comprehensive set of metrics and longitudinal data analysis to confirm conclusions. For example, membership data from the AAN's 2019 Insights Report (personal communication, Orly Avitzur, MD, MBA) reveals that the percentage of women members has been increasing and in 2018 nearly $40 \%$ of all members and 50\% of junior members (i.e., physicians in neurology training programs or postdoctoral fellows in research training programs) were women. Therefore, a reasonable target for equitable presidential representation at the AAN over the next 2 decades would be approximately $40 \%-50 \%$ - or $8-10$ of 20 years or $4-5$ of the ten 2 -year terms. However, to achieve equitable presidential leadership at the AAN, the society's leaders and members will need to analyze and address its culture and processes. As a medical ethicist stated, "Leaders establish and maintain an organization's moral culture, leading to implicit and explicit behavioral norms... The ethical response is to systematically promote women and diverse people into leadership positions." 33

Knowing that some people might assume women do not want to run for or hold elected leadership positions, Shillcutt et al. ${ }^{47}$ published a follow-up survey study of more than 1,200 women physicians, inquiring about their experience and interest in elected positions. We found that $43.8 \%(n=535)$ ran for office during high school and medical school compared with $16.7 \%(n=204)$ thereafter. ${ }^{47}$ However, the majority of women surveyed (nearly 60\%) reported that they would consider running for office at their workplace and 


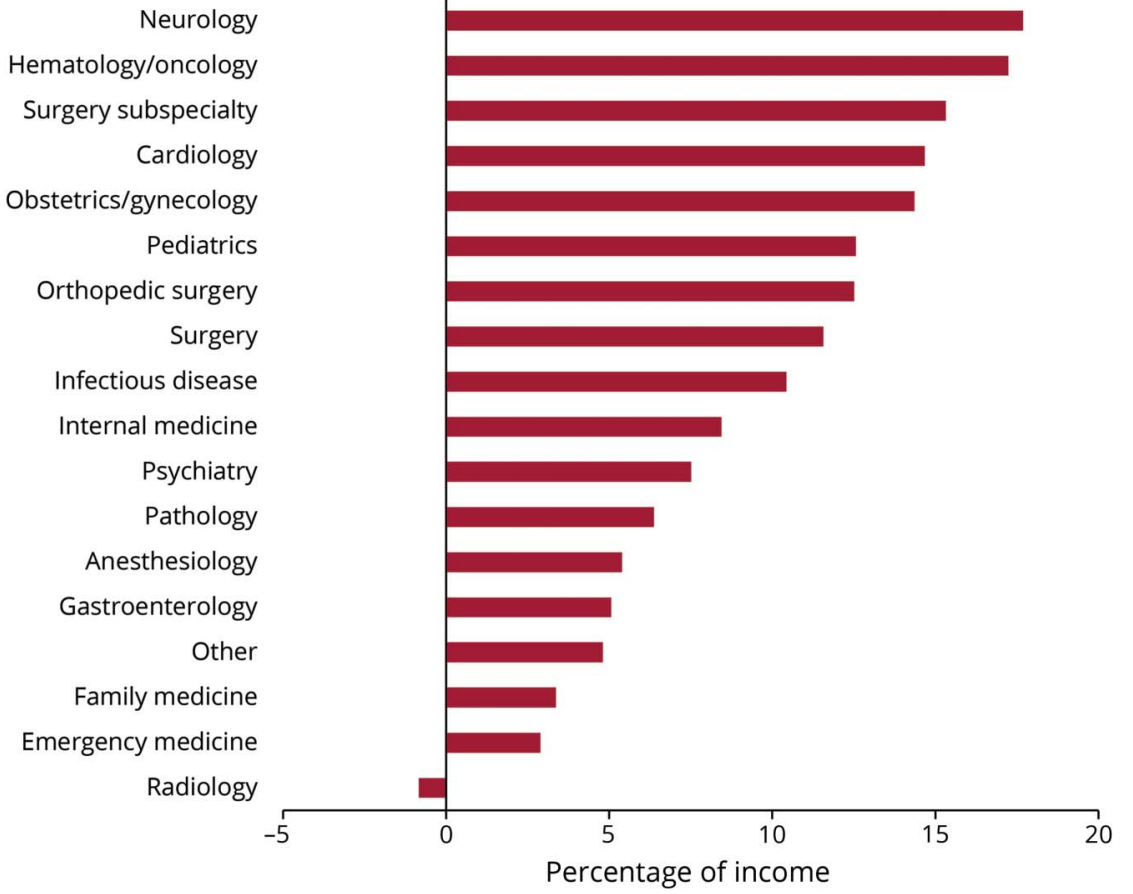

To examine the rank of women academic physicians' salary gap by specialty, the differences between adjusted salaries* of men and women practicing in 18 specialties at 24 US medical schools across 12 states as determined by Jena et al. ${ }^{6}$ were normalized by dividing the differences by the respective adjusted salaries for women academic physicians in the field. Among 18 specialties, women in neurology were ranked no. 1 and face the largest normalized salary gap as percentage of income. *Salary adjustments included those for gender, age, years of experience, faculty rank, scientific authorship, NIH funding, clinical trial participation, and Medicare reimbursements. approximately $50 \%$ would run for office in their medical society in the future. In addition to reporting a loss of family time as a barrier, respondents noted that lack of encouragement by their boss or supervisor was a major obstacle. They also stated that mentorship and gaining further experience would be helpful.

\section{Recognition awards}

In previous work, my colleagues and I also explained the power of zero-citing how an "inexorable zero" (a true zero or near zero level) often has been used by US courts as a prima facie inference of discrimination. Using recognition awards as a metric, we showed that inexorable zeroes existed for women among recipients of recognition awards in 7 medical specialties, including neurology, and in 14 different medical societies, including the AAN and the American Neurological Association. ${ }^{16}$ Subsequently, we studied recipients from the AAN further, concluding the following:

Although it has been more than 2 decades since the proportion of women among US neurologist members of the AAN was lower than 18\%, 1 in 4 AAN award categories demonstrated $0 \%-18 \%$ representation of women among physician recipients during the most recent decade. ${ }^{10}$

Figure 4 Consequences of salary gap on a woman academic physician's personal investment income

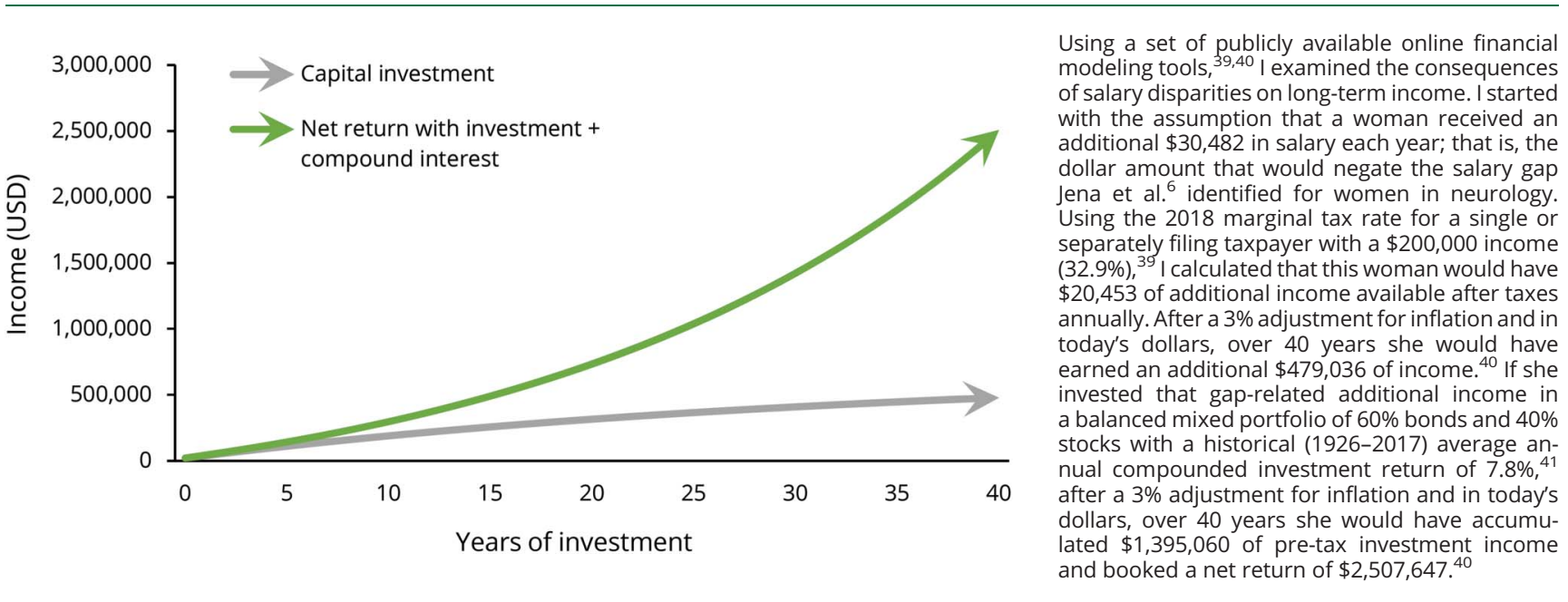


In a letter to the editor published in Neurology regarding our study of AAN recognition awards, one reader attributed the disparities to childbearing, ${ }^{48}$ even though we pointed out that a lack of qualified women neurologists was likely not an issue as there was a sufficiently large and documented pool of highly accomplished candidates at the professor and associate professor levels. ${ }^{49}$ Indeed, causality is multifactorial and not wellunderstood; however, in one study in which we analyzed nomination data, we found that women were nominated for training and early career awards but were not selected by the committee as recipients, while no women were nominated for prestigious later career awards. ${ }^{46}$

\section{Physician burnout and gender disparities}

Physician burnout is a crisis issue among all specialties. However, neurology has been ranked among the top specialties at risk for burnout, ${ }^{50-52}$ and risk is likely more pronounced in women. ${ }^{53}$ Admittedly, there is a need for more research on how bias and discrimination affect symptoms of burnout; nevertheless, it is logical to conclude that treating workers unfairly almost certainly influences how they feel about their job. After all, because promotions tend to increase autonomy and a sense of control, slow or stalled career advancement may increase the risk of burnout. Similarly, maintaining a sense of personal accomplishment (a risk factor for burnout) may be more challenging for women if they are not fairly compensated and valued by others.

\section{Men and the collateral consequences of gender disparities in academic medicine}

To drive change, one must not only understand the various perspectives of those directly affected, but also the perspectives of those who bear witness to what is happening. For example, a man who is in mid or late career is far more likely than a woman at the same stage to have personally benefited from or at least felt supported by an inequitable recognition, reward, and career advancement system. However, because these metrics do not tell the whole story, we might wonder whether men have truly been as fortunate as the data suggest. Moral people must certainly feel a heavy emotional toll when they are participating in, working in, or witnessing an unjust system in which women are systematically mistreated. As the NASEM report points out, sexual harassment negatively affects not only targets but also bystanders who are witness to the mistreatment. $^{28}$ Therefore, even men who have enjoyed the benefits of privilege may be paying an emotional price in the form of moral distress or burnout symptoms if their success is due in part to the systematic oppression of women.

Interestingly, men were undercompensated in one of the specialties examined by Jena et al. ${ }^{6}$-radiology-even after accounting for variables that could affect income. Recently, Google began examining its compensation data as well, and found that in some cases men were being underpaid when compared with women. ${ }^{54}$ Thus, men too are at risk of losing millions of dollars over time due to compensation inequities. Moreover, this risk may increase if women who ascend to leadership positions adopt the practices of current leaders that favor same-gender compensation outcomes. Therefore, it is in everyone's best interest-including men - to use an impartial and scientifically driven approach to compensation that ensures that all workers, regardless of gender, are paid fairly.

\section{Gatekeepers and the collateral consequences of gender disparities in academic medicine}

Career advancement in academic medicine may involve various types of promotion, and advancement from instructor to professor relies on several factors that a promotions committee must consider. Many of these are reported in the curriculum vitae $(\mathrm{CV})$ - a formulaic document that has sections for grant funding, publications, recognition awards, committee assignments, and leadership positions. ${ }^{16}$ Moreover, the number of publications as well as their impact (i.e., bibliometrics such as number of citations and Hirsch index) are part of the analysis. ${ }^{55,56}$ Therefore, although the promotions committee resides at the faculty member's home institution, gender bias or disparities occurring at the level of funding agencies, journals, and medical societies may severely limit a woman's ability to be promoted. While many medical institutions are making large financial investments in improving diversity and gender equity, none of these investments will be fully realized if barriers to women's success are imposed by any of 4 gatekeepers who affect an academician's CV: (1) medical schools/academic medical centers themselves, (2) funding agencies, (3) journals, and (4) medical societies. Importantly, if any of the gatekeepers does not treat women fairly, then the success of efforts (and financial investments) that the others make in driving and achieving diversity and gender equity will be reduced, and ROIs remain unrealized (figure 5).

For example, in a recent study published in JAMA by Oliveira et al., among first-time Principal Investigator NIH grant awardees across all grant types and institutions, women received a median award $\$ 39,106$ less than men $(\$ 126,615$ vs $\$ 165,721$, respectively). At Big Ten and Ivy League universities, where some of the most talented scientists are working, disparities for women amounted to a median difference in funding when compared with men of $\$ 81,711$ and $\$ 19,513$, respectively. These deeply troubling findings highlight the negative consequences of gender disparities on (1) women researchers' ability to obtain grant funding to advance their careers; (2) institutional ROI-often astronomical and incalculable financial and human resource investments made by the home institutions in the recruitment, retention, and success of a large proportion of their scientific workforce ${ }^{18,57-59}$; 


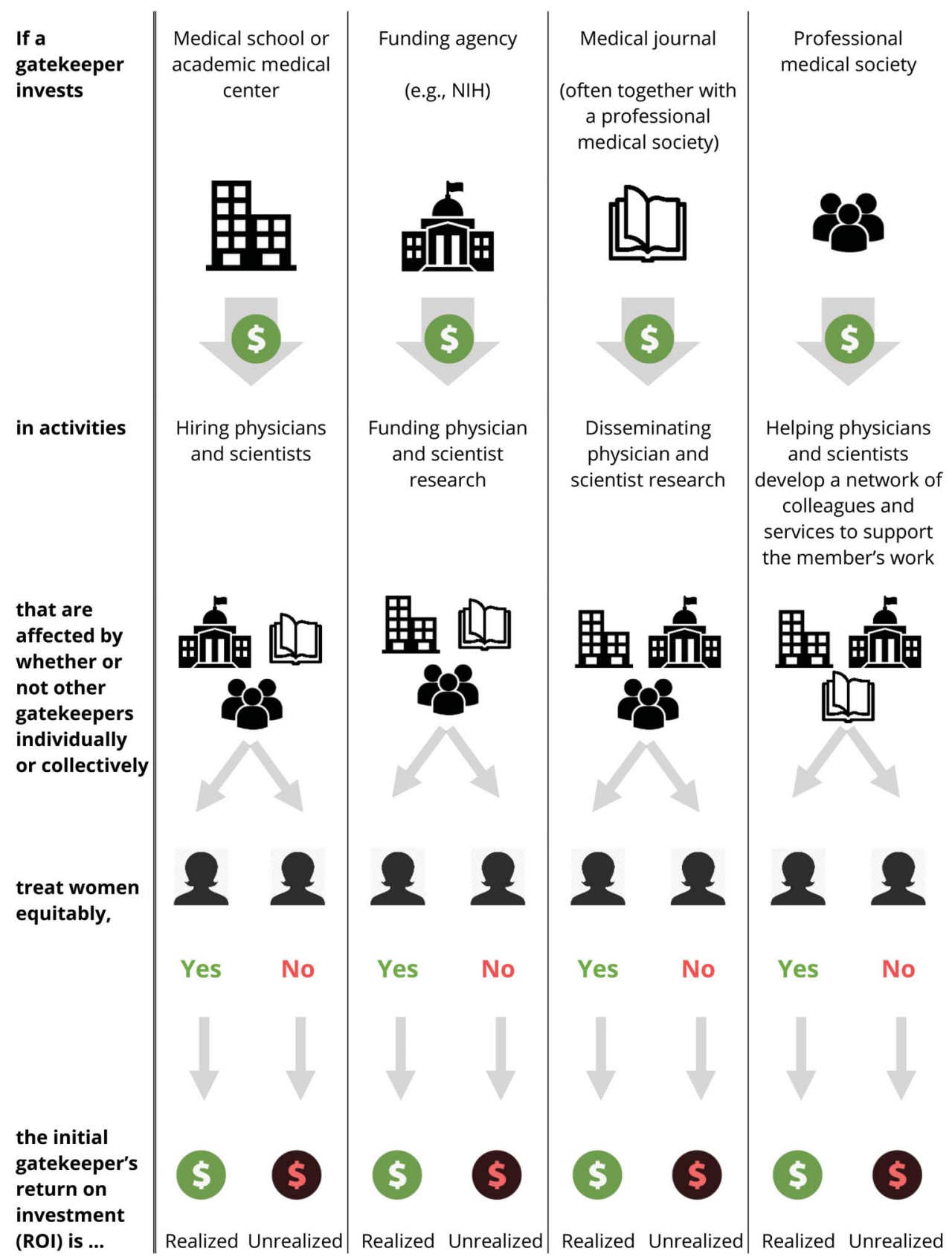

Even if a gatekeeper-an institution whose environment or actions directly affect the careers of physicians and scientists, particularly in academic medicine-makes investments in diversity by hiring, funding, and supporting women, the gatekeeper's return on investment may be negatively affected if any of the other 3 gatekeepers fail to treat them equitably. The icons used in figure 5 were found via Bing search through Microsoft Word's insert online picture function, designed by unknown authors, and inserted unchanged except for colorways under Creative Commons licensing (creativecommons.org/licenses/by/3.0/). and (3) advancement of the science and medicine women are investigating. In addition, disparities in NIH funding of this nature likely reduce the success of administrative efforts of top-level leaders (i.e., deans and chairs, who are mostly men) to support a diverse scientific workforce at the researchers' home institutions. Because gatekeepers are interdependent, even the careers of men at the highest levels of academic medicine may be negatively affected when one or more of the other gatekeepers treats women inequitably.

Similarly, if journals or medical societies demonstrate bias against women in academic medicine-negatively affecting their ability to publish, present, or be recognized for their work through recognition awards, plenary or other lectures, and newsletter articles-then financial and other negative consequences may extend far beyond the women who are most directly affected, to their home institutions and funding agencies. Medical schools and academic medical centers, too, may be inadvertently undermining the investments that other organizations are making. For instance, the AAN has invested financial and other resources in the Women Leading in Neurology program. If women neurologists who have committed their time have lost clinical compensation or have self-funded their participation are not provided equitable 
opportunities for advancement in their workplace, the AAN's ROI of financial, administrative, and human resources is reduced as well. Treating women in medicine unfairly hurts everyone-obstructing women who seek career advancement, impeding their leaders (mostly men) who are charged with improving diversity and inclusion, and causing unrealized ROI for many organizations (institutions, funding agencies, journals, and societies) in the health care system.

\section{Driving gender equity in academic medicine}

The best way to accelerate gender equity for women in academic medicine is for all of the gatekeepers to hold each other accountable. This means that they must turn away from leaders who are supporting the status quo or the normalization of gender discrimination and sexual harassment and toward ethical leaders who are committed to organizational culture and climate change. In 2018, I developed the Be Ethical Campaign $^{60}$ to encourage leaders in the key gatekeeper groups to use a 6-step process (table 1) and a comprehensive set of unique and customizable metrics with longitudinal data analysis to uncover, address, and accelerate workforce gender equity, including the removal of bias, discrimination, and harassment. Avoiding critical thinking errors during this process is crucial, because they are pervasive in gender equity discussions and tend to slow or derail efforts (table 2). ${ }^{60}$

Importantly, every medical specialty, including neurology, needs to examine its own history, particularly over the last 2 decades, as this is the timeframe most relevant to the majority of women who are in the specialty currently and interventions enacted now will affect their career trajectory for the coming years. What might an ethical path forward in neurology look like for midcareer US women neurologists who have been represented at markedly disproportionate levels as professors, department chairs, medical society presidents, recognition award recipients,

Table 1 Systematic 6-step process toward achieving organizational gender equity ${ }^{a}$

\begin{tabular}{ll}
\hline Step & Action \\
\hline $\mathbf{1}$ & $\begin{array}{l}\text { Examine gender data through the lens of an organization's mission, } \\
\text { values, and ethical code of conduct }\end{array}$ \\
\hline $\mathbf{2}$ & Report the results transparently to all stakeholders \\
\hline $\mathbf{3}$ & Investigate causes of disparities \\
\hline $\mathbf{4}$ & Implement strategies to address disparities \\
\hline $\mathbf{6}$ & Track outcomes and adjust strategies as needed \\
\hline
\end{tabular}

Health care institutions and affiliated organizations must take a systematic approach to addressing gender disparities that involves unique and customized but defined metrics and transparent reporting to all stakeholders. $^{60}$

a Table reproduced with permission from the Be Ethical Campaign report. and senior editors of neurology journals and who have not received equitable compensation or research funding? If the situation was reversed and over the last 2 decades a large body of evidence showed that men were not fairly compensated, promoted, or recognized, and they were often ignored and silenced, what would today's leaders do now to address this?

Many organizations have been increasing their efforts to address gender equity, inclusion, and safety, and, while a complete list is beyond the scope of this report, some examples include the following: Association of American Medical Colleges' "Promising Practices for Understanding and Addressing Salary Equity at US Medical Schools"61 ; American College of Physicians' "Achieving Gender Equity in Physician Compensation and Career Advancement" ${ }^{\text {"6 }}$; Association of Women Surgeons' "Strategies for Identifying and Closing the Gender Salary Gap in Surgery"63; American Surgical Association's "Ensuring Equity, Diversity, and Inclusion in Academic Surgery" ${ }^{24,65}$; and the American Medical Women's Association's "Revolution by Resolution." ${ }^{\circ 6}$ Moreover, professional societies and other organizations are launching initiatives aimed at working together and sharing resources and best practices. For example, the American Academy of Pediatrics, American Academy of Family Physicians, American College of Physicians, American College of Obstetricians and Gynecologists, American Psychiatric Association, and American Hospital Association recently launched “Women's Wellness through Equity and Leadership," 67 which will train a cohort of health care professionals in critical leadership skills and develop principles regarding healthy work environments for physicians.

Recently, neurologists have been focusing on their own culture of diversity and inclusion, including but not limited to equity for women neurologists, and both formal and informal initiatives and networks are supporting this work. Table 3 lists some important initiatives by neurology organizations, including the AAN's Women's Leadership Program, which are focused on closing leadership gaps and addressing other disparities for women in neurology. Still, the field has some catching up to do, and "recent data in neurology show that we lag behind the rest of medicine with continued gender disparities." ${ }^{38}$ In an editorial I wrote titled "Can neurologists come from behind and lead the way in physician gender equity?"68 I commented that this specialty might be the dark horse that surprises us all, in part because neurologists are used to solving challenging problems and embracing scientific methodology. I recommended getting 2 houses in equitable order as quickly as possible-neurology medical societies and journals-because these organizational gatekeepers tend to set the tone for a specialty. Further, if the most influential leaders from the 4 gatekeeper groups in neurology convened and each agreed to use the 6-step process outlined in table 1, neurology would be among the first specialties to use an aligned and scientifically driven strategy to accelerate progress for women in medicine. Neurologists need to unite and commit to treating their talented women fairly. When that happens, everyone wins. 
Table 2 Critical thinking errors related to gender equity ${ }^{25}$

\begin{tabular}{ll}
\hline Critical thinking error & Example \\
\hline Perpetuating myths & $\begin{array}{l}\text { Leaders and colleagues thinking that there are not enough qualified women to fill positions, } \\
\text { particularly leadership positions }\end{array}$ \\
$\begin{array}{ll}\text { Holding the affected group responsible for the } \\
\text { problem }\end{array}$ & $\begin{array}{l}\text { Leaders and colleagues blaming women for gender-related disparities in compensation, } \\
\text { promotion, and publishing, and expecting women to fix the disparities themselves }\end{array}$ \\
\hline $\begin{array}{l}\text { Preserving willful ignorance about the problem } \\
\text { Presuming that the affected group should conform } \\
\text { to the establishment culture }\end{array}$ & $\begin{array}{l}\text { Failure of institutional and organizational leaders and colleagues to read, understand, and } \\
\text { respond in a timely manner to the growing evidence-based gender disparity literature }\end{array}$ \\
\hline $\begin{array}{l}\text { Leaders and colleagues failing to understand that outdated organizational processes, criteria, and } \\
\text { rules-such as, but not limited to, hiring and admission practices and evaluation and promotion } \\
\text { standards-may not support equitable inclusion of a diverse workforce }\end{array}$
\end{tabular}

\section{Discussion}

At this unique time in history, there is an opportunity for leaders in neurology to strategically and expeditiously address its workforce gender disparities. To do so, there will need to be a concerted effort among the 4 gatekeeper organizations: (1) medical schools/academic medical centers, (2) government and other funding agencies, (3) neurology journals, and (4) neurology professional societies. Leaders will have to plan an intentional path forward, and in their own organizations overcome barriers to an equitable and safe work environment for women. Moreover, leaders in all 4 types of organizations must hold each other accountable for gender equity as their own success and financial ROI is dependent on the efforts of those in the other categories. In short, the path forward is to focus on ethical principles and behavior when it comes to addressing workforce gender disparities for women in medicine.

\section{Author contributions}

J.K. Silver: drafting/revising the manuscript, data acquisition, study concept or design, analysis or interpretation of data, accepts responsibility for conduct of research and final approval, acquisition of data, statistical analysis.

\section{Acknowledgment}

The author thanks Orly Avitzur, MD, MBA, FAAN, AAN President-Elect nominee; Divya Singhal, MD; Kathrin LaFaver, MD, FAAN; and Amy Nostdahl, Senior Manager for Leadership Development at the AAN, for providing information about various initiatives that support women in neurology; and Julie Poorman, $\mathrm{PhD}$, for her assistance with manuscript preparation. The icons used in figure 5 were found via Bing search through Microsoft Word's insert online picture function, designed by unknown authors, and inserted unchanged except for colorways under Creative Commons licensing (creativecommons.org/licenses/by/3.0/).

\section{Study funding}

No targeted funding reported.

\section{Disclosure}

J.K. Silver has personally funded the Be Ethical Campaign and proceeds from the campaign support disparities research. As an academic physician, J. K. Silver has published books and receives royalties from book publishers, and she gives professional talks such as grand rounds and medical conference plenary lectures and receives honoraria from conference organizers. J.K. Silver has grant funding from

Table 3 Organizational initiatives for women in neurology ${ }^{a}$

\begin{tabular}{|c|c|c|}
\hline Sponsor & Initiative & Description and purpose \\
\hline \multirow[t]{3}{*}{ AAN } & $\begin{array}{l}\text { Leadership for Women } \\
\text { Subcommittee }\end{array}$ & $\begin{array}{l}\text { Subcommittee of the Leadership Development Committee responsible for the following: } \\
\text { - Development and implementation of the Women Leading in Neurology Program } \\
\text { - Implementation of additional annual meeting and regional programming focusing on women in leadership }\end{array}$ \\
\hline & $\begin{array}{l}\text { Women Leading in } \\
\text { Neurology Program }\end{array}$ & $\begin{array}{l}\text { A 1-year midcareer leadership training program for up to } 12 \text { women neurologists requiring the following: } \\
\text { - Participants to attend leadership retreats, coaching calls, and small group calls } \\
\text { - The AAN to cover all program-related expenses for the selected participants }\end{array}$ \\
\hline & $\begin{array}{l}\text { Women's Issues in } \\
\text { Neurology Section }\end{array}$ & $\begin{array}{l}\text { Section of the AAN, with nearly } 800 \text { members, focused on the following: } \\
\text { - Integrating sex and gender into neurology research } \\
\text { - Supporting women neurologists' careers through activities such as mentorship network, speaker } \\
\text { nominations, committee membership, and FAAN applications }\end{array}$ \\
\hline
\end{tabular}

Independent Women's Neurology Group

Facebook group of more than 2,500 members that provides an online community through which women neurologists can share professional information and expand their professional network

Abbreviations: AAN = American Academy of Neurology; FAAN = Fellow of the American Academy of Neurology.

a This is not intended to be a complete list. 
The Arnold P. Gold Foundation (physician and patient care disparities research) and Binational Scientific Foundation (culinary telemedicine research). Go to Neurology.org/N for full disclosures.

\section{Publication history}

Received by Neurology March 27, 2019. Accepted in final form June 12, 2019.

\section{References}

1. Kirch DG; Association of American Medical Colleges. AAMC News: a landmark for women in medicine. Available at: news.aamc.org/medical-education/article/wordpresident-landmark-women-medicine/. Published 2018. Accessed March 14, 2019.

2. Helitzer DL, Newbill SL, Cardinali G, Morahan PS, Chang S, Magrane D. Changing the culture of academic medicine: critical mass or critical actors? J Womens Health 2017;26:540-548.

3. Bickel J. Women in medicine: evidence that more evidence is insufficient in effecting improvements. Acad Med 2017;92:274.

4. Silver JK, Blauwet CA, Bhatnagar S, et al. Women physicians are underrepresented in recognition awards from the Association of Academic Physiatrists. Am J Phys Med Rehabil 2018;97:34-40.

5. Amrein K, Langmann A, Fahrleitner-Pammer A, Pieber TR, Zollner-Schwetz I. Women underrepresented on editorial boards of 60 major medical journals. Gend Med 2011;8:378-387.

6. Jena $A B$, Olenski AR, Blumenthal DM. Sex differences in physician salary in US public medical schools. JAMA Intern Med 2016;176:1294-1304.

7. Jena AB, Khullar D, Ho O, Olenski AR, Blumenthal DM. Sex differences in academic rank in US medical schools in 2014. JAMA 2015;314:1149-1158.

8. Oliveira DFM, Ma Y, Woodruff TK, Uzzi B. Comparison of National Institutes of Health grant amounts to first-time male and female principal investigators. JAMA 2019;321:898-900.

9. Silver JK, Bhatnagar S, Blauwet CA, et al. Female physicians are underrepresented in recognition awards from the American Academy of Physical Medicine and Rehabilitation. PM R 2017;9:976-984.

10. Silver JK, Bank AM, Slocum CS, et al. Women physicians underrepresented in American Academy of Neurology recognition awards. Neurology 2018;91. e603-e614.

11. Ellinas EH, Rebello E, Chandrabose RK, Shillcutt SK, Hernandez M, Silver JK. Distinguished service awards in anesthesiology specialty societies: analysis of gender differences. Anesth Analg Epub 2019 Mar 17.

12. Kennedy BL, Lin Y, Dickstein LJ. Women on the editorial boards of major journals. Acad Med 2001;76:849-851.

13. Silver JK, Poorman JA, Reilly JM, Spector ND, Goldstein R, Zafonte RD. Assessment of women physicians among authors of perspective-type articles published in highimpact pediatric journals. JAMA Netw Open 2018;1:e180802.

14. Larson AR, Poorman JA, Silver JK. Representation of women among physician authors of perspective-type articles in high impact dermatology journals. JAMA Dermatol 2019 (in press 2019).

15. Boiko JR, Anderson AJM, Gordon RA. Representation of women among academic Grand Rounds speakers. JAMA Intern Med 2017;177:722-724.

16. Silver JK, Slocum CS, Bank AM, et al. Where are the women? The underrepresentation of women physicians among recognition award recipients from medical specialty societies. PM R 2017;9:804-815.

17. Files JA, Mayer AP, Ko MG, et al. Speaker introductions at internal medicine Grand Rounds: forms of address reveal gender bias. J Womens Health 2017;26:413-419.

18. Martinez LR, O'Brien KR, Hebl MR. Fleeing the ivory tower: gender differences in the turnover experiences of women faculty. J Womens Health 2017;26:580-586.

19. Association of American Medical Colleges. Table 13: US medical school faculty by sex, rank, and department, 2018. Available at: aamc.org/download/495048/data/ 18table13.pdf. Published 2019. Accessed March 13, 2019.

20. McDermott M, Gelb DJ, Wilson K, Pawloski JF, Shelgikar AV, London ZN. Sex differences in academic rank and publication rate at top-ranked US neurology programs. JAMA Neurol 2018;75:956-961.

21. Schor NF. The decanal divide: women in decanal roles at US medical schools. Acad Med 2018;93:237-240.

22. Lillemoe KD. Surgical mentorship: a great tradition, but can we do better for the next generation? Ann Surg 2017;266:401-410.

23. Carr PL, Gunn C, Raj A, Kaplan S, Freund KM. Recruitment, promotion, and retention of women in academic medicine: how institutions are addressing gender disparities. Womens Health Issues 2017;27:374-381.

24. Carnes M, Morrissey C, Geller SE. Women's health and women's leadership in academic medicine: hitting the same glass ceiling? J Womens Health 2008;17:1453-1462.

25. Silver JK, Rowe M, Sinha MS, Molinares DM, Spector ND, Mukherjee D. Microinequities in medicine. PM R 2018;10:1106-1114

26. Silver JK, Reilly JM, Gallegos-Kearin V, Poorman JA, Bhatnagar S, Zafonte R. Women physicians are often not visible in newsletters published by the American Academy of Physical Medicine and Rehabilitation. Paper presented at the Annual Assembly of American Academy of Physical Medicine and Rehabilitation; October 25-28, 2018; Orlando, FL.
27. Woolston C. Recognition: build a reputation. Nature 2015;521:113-115.

28. National Academies of Sciences, Engineering, and Medicine. Sexual Harass ment of Women: Climate, Culture, and Consequences in Academic Sciences, Engineering, and Medicine. Washington, DC: The National Academies Press; 2018.

29. Collins FS, Tabak LA, Wolinetz CD, et al. Update on NIH's efforts to address sexual harassment in science. National Institutes of Health. Available at: nih.gov/about-nih/ who-we-are/nih-director/statements/update-nihs-efforts-address-sexual-harassmentscience. Published 2019. Accessed March 14, 2019.

30. National Institutes of Health. Anti-sexual harassment. Available at: nih.gov/antisexual-harassment. Published 2018. Accessed March 12, 2019.

31. Thielking M. Time's Up sets its sights on gender bias and harassment in health care. STAT. Available at: statnews.com/2019/02/28/times-up-health-care-bias-harassment/. Published 2019. Accessed March 13, 2019.

32. American College of Physicians. ACP Ethics Manual. 6th ed. 2012. Available at: acponline.org/clinical-information/ethics-and-professionalism/acp-ethics-manualsixth-edition/acp-ethics-manual-sixth-edition. Accessed February 22, 2019.

33. Burgart AM. Physician sexual assault: the moral imperative for gender equity in medicine. Am J Bioeth 2019;19:4-6.

34. Association of American Medical Colleges. Table 2.2: Number and percentage of ACGME residents and fellows by sex and specialty, 2017. Available at: aamc.org/ data/workforce/reports/492576/2-2-chart.html. Published 2018. Accessed March 25, 2019.

35. Association of American Medical Colleges. Table 1.3: Number and percentage of active physicians by sex and specialty, 2017. Available at: aamc.org/data/workforce/ reports/492560/1-3-chart.html. Published 2017. Accessed March 13, 2019.

36. Cordonnier C, Coutts SB, Johnston KC, Rost NS. Crucial role of women's leadership in academic stroke medicine. Stroke 2019;50:e149-e152.

37. Silver JK, Ghalib R, Poorman JA, Al-Assi S, Bhargava H, Shillcutt SK Analysis of gender equity in leadership of physician-focused medical specialty societies, 2008 2017. JAMA Intern Med Epub 2019 Jan 7.

38. Graves JS, Brashear A. Gender bias in American Academy of Neurology recognition awards? Neurology 2018;91:291-292.

39. KJE Computer Solutions, Inc. Marginal tax rate calculator for 2018. Available at: dinkytown.net/java/marginal-tax-rate-calculator.html\#. Accessed March 20, 2019.

40. KJE Computer Solutions, Inc. Investment returns. Available at: dinkytown.net/java/ investment-returns.html. Accessed March 20, 2019.

41. The Vanguard Group. Vanguard portfolio allocation models. Available at: personal. vanguard.com/us/insights/saving-investing/model-portfolio-allocations?lang=en. Accessed March 19, 2019.

42. Silver JK. Gender equity on journal editorial boards. Lancet 2019;393:2037-2038.

43. Hengel E. Publishing while female: are women held to higher standards? Evidence from peer review. Cambridge, UK: University of Cambridge; 2017.

44. Lundine J, Bourgeault IL, Clark J, Heidari S, Balabanova D. The gendered system of academic publishing. Lancet 2018;391:1754-1756.

45. Gross RA; American Academy of Neurology. Editorial changes at Neurology. Available at: aan.com/AAN-Resources/Details/contact-aan/. Published 2019. Accessed May 24, 2019

46. Silver JK, Cuccurullo SJ, Ambrose AF, et al. Association of academic physiatrists women's task force report. Am J Phys Med Rehabil 2018;97:680-690.

47. Shillcutt S, Parangi S, Diekman S, et al. Survey of women physicians' experience with elected leadership positions. Health Equity 2019;3:162-168.

48. Ortega M. Reader response: women physicians underrepresented in American Academy of Neurology recognition awards. Neurology 2019;92:923.

49. Bank AM, Slocum CS, Blauwet CA, et al. Author response: women physicians underrepresented in American Academy of Neurology recognition awards. Neurology 2019;92:924.

50. Peckham C. Medscape national physician burnout \& depression report. Available at: medscape.com/slideshow/2018-lifestyle-burnout-depression-6009235\#1. Published 2018. Accessed March 14, 2019.

51. Dyrbye LN, Burke SE, Hardeman RR, et al. Association of clinical specialty with symptoms of burnout and career choice regret among US resident physicians. JAMA 2018;320:1114-1130.

52. Shanafelt TD, Boone S, Tan L, et al. Burnout and satisfaction with work-life balance among US physicians relative to the general US population. Arch Intern Med 2012; 172:1377-1385

53. Moore LR, Ziegler C, Hessler A, Singhal D, LaFaver K. Burnout and career satisfaction in women neurologists in the U.S. J Womens Health2019;28: $515-525$

54. Wakabayashi D. Google finds it's underpaying many men as it addresses wage equity. The New York Times. Available at: nytimes.com/2019/03/04/technology/googlegender-pay-gap.html?fbclid=IwAR1ijM1IstbM-El_L1_ZVO-

t7RolMKcXOlOYI3G2pwfO1GM1R_7uzYNLLn_c. Published 2019. Accessed March 14, 2019

55. Yang HY, Rhee G, Xuan L, Silver JK, Jalal S, Khosa F. Analysis of H-index in assessing gender differences in academic rank and leadership in physical medicine and rehabilitation in the United States and Canada. Am J Phys Med Rehabil 2019;98 479-483.

56. Knowlton SE, Paganoni S, Niehaus W, et al. Measuring the impact of research using conventional and alternative metrics. Am J Phys Med Rehabil 2019;98:331-338.

57. Hamidi MS, Bohman B, Sandborg C, et al. Estimating institutional physician turnover attributable to self-reported burnout and associated financial burden: a case study BMC Health Serv Res 2018;18:851. 
Grigsby K. Association of American Medical Colleges. Faculty turnover costs in academic medicine and science. Available at: aamc.org/members/gwims/resources/ 397190/costofturnovergrigsby.html. Accessed March 18, 2019.

59. Schloss EP, Flanagan DM, Culler CL, Wright AL. Some hidden costs of faculty turnover in clinical departments in one academic medical center. Acad Med 2009;84:32-36.

60. Silver JK. \#BeEthical: a call to healthcare leaders: ending gender workforce disparities is an ethical imperative. Available at: sheleadshealthcare.com/wp-content/uploads/ 2018/10/Be_Ethical_Campaign_101418.pdf. Published September 17, 2018. Accessed March 13, 2019.

61. Dandar VM, Lautenberger DM, Garrison GE. Promising Practices for Understanding and Addressing Salary Equity at US Medical Schools. Washington, DC: Association of American Medical Colleges; 2019.

62. Butkus R, Serchen J, Moyer DV, Bornstein ST. Achieving gender equity in physician compensation and career advancement: a position paper of the American College of Physicians. Ann Intern Med 2018;168:721-723.
63. Sanfey H, Crandall M, Shaughnessy E, Stein A, Parangi S, Laronga C. Strategies for identifying and closing the gender salary gap in surgery. J Am Coll Surg 2017;225: 333-338.

64. Task Force on Equity, Diversity, and Inclusion. Ensuring Equity, Diversity, and Inclusion in Academic Surgery. Beverly, MA: American Surgical Association; 2018.

65. West MA, Hwang S, Maier RV, et al. Ensuring equity, diversity, and inclusion in academic surgery: an American Surgical Association white paper. Ann Surg 2018;268: 403-407.

66. American Medical Women's Association. Revolution by resolution: advancing gender equity in medical societies state by state. Available at: amwa-doc.org/revolution-by resolution/. Published 2019. Accessed March 13, 2019.

67. Korioth T; American Academy of Pediatrics. Project aims to support female physicians in wellness, equity, leadership. Available at: aappublications.org/news/2019/ 02/26/wel022619. Published 2019. Accessed May 24, 2019.

68. Silver JK. Can neurologists come from behind and lead the way in physician gender equity? J Womens Health 2019;28:421-422.

\section{The AAN is Fighting for You!}

In the midst of rapid changes in health care policy, the AAN has your back. From actively lobbying members of Congress to meeting with regulators to underscore the value of neurology and your services to your patients, the Academy is forcefully countering any threats to your profession and patient access to care. Learn more at AAN.com/policy-and-guidelines/advocacy, read the bimonthly Capitol Hill Report and monthly AANnews ${ }^{\circledR}$ member magazine, and respond to Advocacy Action Alert emails when we invite you to share your voice with Congress.

\section{Committed to Making a Difference: 2020 American Academy of Neurology Research Program}

The American Academy of Neurology (AAN) is committed to making a profound difference in the lives of researchers, in turn making a difference in the lives of patients with brain disease. The ambitious 2020 AAN Research Program offers opportunities ranging from $\$ 130,000$ to $\$ 450,000$ and is designed for all types of research across all career levels and discovery stages. Pave your own pathway to patient care by applying for one of the opportunities by the October 1, 2019, deadline.

Visit AAN.com/view/ResearchProgram today.

\section{Share Your Artistic Expressions in Neurology 'Visions'}

AAN members are urged to submit medically or scientifically related artistic images, such as photographs, photomicrographs,

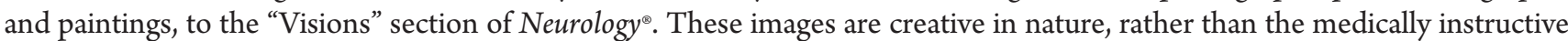
images published in the NeuroImages section. The image or series of up to six images may be black and white or color and must fit into one published journal page. Accompanying description should be 100 words or less; the title should be a maximum of 96 characters including spaces and punctuation.

Please access the Author Center at NPub.org/authors for full submission information. 


\section{Neurology}

\section{Understanding and addressing gender equity for women in neurology Julie K. Silver \\ Neurology 2019;93;538-549 Published Online before print July 31, 2019 \\ DOI 10.1212/WNL.0000000000008022}

This information is current as of July 31, 2019

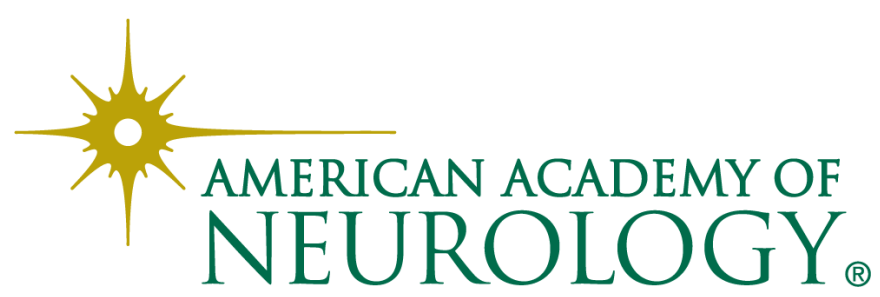




\section{Updated Information \& Services}

References

Citations

Subspecialty Collections

Permissions \& Licensing

\section{Reprints}

including high resolution figures, can be found at: http://n.neurology.org/content/93/12/538.full

This article cites 42 articles, 4 of which you can access for free at: http://n.neurology.org/content/93/12/538.full\#ref-list-1

This article has been cited by 14 HighWire-hosted articles: http://n.neurology.org/content/93/12/538.full\#\#otherarticles

This article, along with others on similar topics, appears in the following collection(s):

\section{All Ethics in Neurology/Legal issues}

http://n.neurology.org/cgi/collection/all_ethics_in_neurology_legal_iss ues

All Rehabilitation

http://n.neurology.org/cgi/collection/all_rehabilitation

CME

http://n.neurology.org/cgi/collection/cme

Inclusion, Diversity, Equity, Anti-racism, and Social Justice

(IDEAS)

http://n.neurology.org/cgi/collection/all_equity_diversity_and_inclusio $\mathrm{n}$

Methods of education

http://n.neurology.org/cgi/collection/methods_of_education

Professional conduct and ethics

http://n.neurology.org/cgi/collection/professional_conduct_and_ethics

Information about reproducing this article in parts (figures,tables) or in its entirety can be found online at:

http://www.neurology.org/about/about_the_journal\#permissions

Information about ordering reprints can be found online:

http://n.neurology.org/subscribers/advertise

Neurology ${ }^{\circledR}$ is the official journal of the American Academy of Neurology. Published continuously since 1951, it is now a weekly with 48 issues per year. Copyright @ 2019 American Academy of Neurology. All rights reserved. Print ISSN: 0028-3878. Online ISSN: 1526-632X.

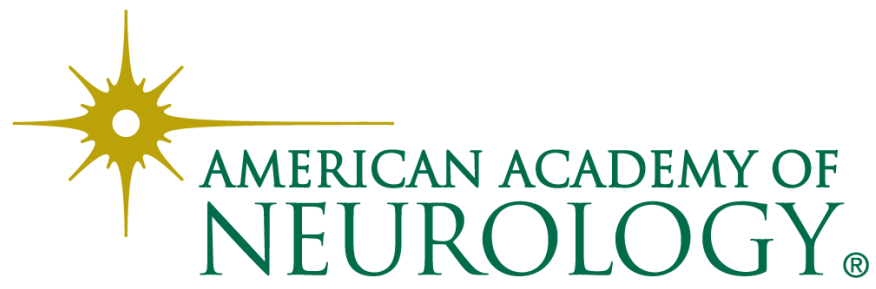

